\title{
LA CRÓNICA TAURINA: EL ETHOSRETÓRICO DE VICENTE ZABALA Y JOAQUÍN VIDAL
}

\section{BULLFIGHTING REPORT: THE RHETORICAL ETHOS OF VICENTE ZABALA AND JOAQUÍN VIDAL}

\section{AUTORA}

\section{Dra. Ma Almudena Hernández Pérez}

Redactora de la Agencia de Noticias Servimedia y Responsable taurina de LaSemana.es. Madrid (España).

ahernandez@lasemana.es

\section{RESUMEN}

Este artículo está basado en la tesis doctoral “J. M. Arroyo Joselito. Análisis de sus actuaciones en la plaza de Las Ventas: las crónicas de $A B C$ y El País". Parte de la hipótesis de que el ethos o carácter retórico del autor configura las distintas partes que estructuran un género tan particular como es la crónica taurina. El trabajo de investigación lo demuestra a través de diversos análisis de las crónicas que escribieron dos de los maestros del periodismo taurino de finales del siglo XX, Vicente Zabala, en el diario $A B C$, y J oaquín Vidal, en El País. Para acotar el objeto de estudio, la tesis se basó únicamente en las crónicas que ambos publicaron sobre las actuaciones de uno de los toreros más destacados de las dos últimas décadas del siglo XX, el diestro José Miguel Arroyo Joselito, y en la misma plaza de toros, la de Las Ventas de Madrid. 


\section{PALABRAS CLAVE}

Crónica taurina - ethos - Vicente Zabala - J oaquín Vidal

\section{ABSTRACT}

This report is based on the doctoral thesis "J. M. Arroyo Joselito. Análisis de sus actuaciones en la plaza de Las Ventas: las crónicas de $A B C$ y El País". The starting point is the hypothesis in which the ethos or author's rhetorical character represents the different parts that form such a special journalistic genre, the bullfighting report. That hypothesis has been proved by several analytical studies about the reports written by Vicente Zabala ( $A B C$ ) and Joaquín Vidal ( $E /$ País), two master bullfighting journalists at the end XXth century. To delimit the subject of the research, the thesis focuses on the reports that both writers have published about José Miguel Arroyo Joselito, one of the most distinguished bullfighters in the last two decades of the XXth century, in the same bullring, Las Ventas in Madrid.

\section{KEY WORDS}

Bullfighting report - ethos - Vicente Zabala - J oaquín Vidal

\section{ÍNDICE}

\section{Introducción}

2. Cómo acercarse al ethos de los periodistas

3. Un análisis múltiple del ethos retórico

3.1 La búsqueda del ethos en las crónicas de Vicente Zabala

3.1.1 Breve repaso biográfico a Vicente Zabala

3.1.2 Manifestaciones del ethos de las crónicas de Zabala

3.2 La búsqueda del ethos en las crónicas de J oaquín Vidal

3.2.1 Breve repaso biográfico a J oaquín Vidal

3.2.2 Manifestaciones del ethos de las crónicas de Vidal

4. A modo de conclusión 


\section{Introducción}

Sería un trabajo fascinante: con esta suposición nos adentramos en la elaboración de la tesis doctoral "J. M. Arroyo Joselito. Análisis de sus actuaciones en la plaza de Las Ventas: las crónicas de $A B C$ y $E /$ País". Estudiar el ethos retórico de un periodista implica aproximarse al alma de su creador, pero también en las personas de las que habla en sus trabajos, en este caso, el torero Joselito. Se supone que una persona es también lo que otros dicen que es y la imagen que proyecta a su entorno.

Analizar las magistrales crónicas taurinas de Vicente Zabala y Joaquín Vidal en la citada tesis conllevó una inmersión en la historia del periodismo, prestando especial atención al taurino. Para ello, partimos de la definición de crónica taurina que hizo en su día la directora de esta tesis, la profesora María Celia Forneas: "Un texto informativo, literario y de opinión" (Forneas, 1998).

No podemos olvidar que la auténtica crónica taurina es un género periodístico de autor, único y especial, que refleja el talante o ethos del cronista. En parte por ello, en la tesis "J. M. Arroyo Joselito. Análisis de sus actuaciones en la plaza de Las Ventas: las crónicas de $A B C$ y $E /$ País" decidimos investigar sobre el ethos en las crónicas de Zabala y Vidal, pero también averiguar si de la mera intuición se puede pasar a la demostración de que el ethos funciona como elemento que configura las diferentes partes del texto.

Para descubrirlo trazamos algunos límites para acotar el objeto de estudio: sólo nos ocuparíamos de las crónicas que dos periodistas escribieron sobre las actuaciones de un mismo torero y en un mismo escenario. $Y$ en las décadas de los años 80 y 90 del siglo $\mathrm{XX}$, en las que la autora de la tesis desarrolló especialmente su afición a la Fiesta brava, destacaban especialmente las plumas de Vicente Zabala y J oaquín Vidal 
como las primeras del periodismo taurino. También por entonces, J osé Miguel Arroyo Joselito era un mandamás entre los toreros y quizás el más querido por el exigente público de la plaza de Las Ventas de Madrid, considerada la más importante del mundo. La tesis confirmó que, efectivamente, el ethos estructura las crónicas taurinas analizadas, en las que coincidían todos esos ingredientes.

\section{Cómo acercarse al ethos de los periodistas}

Pero el trabajo, además de apasionante, fue largo y minucioso. Queríamos acercarnos al máximo al talante o ethos de los dos periodistas taurinos, y para ello creímos conveniente abordar un análisis múltiple. Observamos las crónicas de Vicente Zabala y Joaquín Vidal teniendo en cuenta que son resultado de una mezcla de información, literatura y opinión. Pero también vimos que ambos combinaron en sus escritos su categoría periodística, los amplísimos conocimientos taurinos que acumularon, y el peculiar, específico y amplio vocabulario con el que se expresan los entendidos en Tauromaquia. De este modo descubrimos que Zabala y Vidal tuvieron que esquivar diversas dificultades cuando redactaban sus crónicas. Esas circunstancias, como es obvio, dejan huella en la manifestación de su ethos en las líneas que ambos firmaron.

Practicando la empatía, tratamos de ponernos en la situación a la que se enfrentaban los periodistas cada vez que acudían a Las Ventas a ver una corrida en la que participaba J osé Miguel Arroyo y, sobre todo, al redactar sus crónicas. Tampoco para ellos fue fácil. Por ejemplo, debían considerar que tenían ciertos lectores no iniciados y que éstos podían tener problemas de comprensión ante estas piezas periodísticas que abordan temáticas muy amplias con un vocabulario muy especial.

Además, aunque las tecnologías de la información y la comunicación avanzan vertiginosamente, todavía había ciertas carencias en los años estudiados. Por entonces, las corridas de toros de la Feria de San Isidro de Madrid solían finalizar cuando los periódicos debían cerrar o ya deberían haber cerrado su primera edición. 


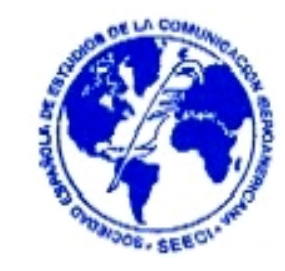

Es decir, que toda la redacción estaba pendiente de que el periodista taurino firmase su crónica del día para asegurarse de que el periódico del día siguiente se imprimiría a tiempo para ser distribuido.

El crítico taurino Javier Villán, que conoció a Zabala y a Vidal, asegura que "la primera edición presenta las mismas urgencias, el oficio sustituye a la reflexión y el hábito de la cultura pone el toque literario, histórico o sociológico que requiere la crónica"(Villán, 2007, p. 19).

Los periodistas practicaban una especial ceremonia. Acudían a Las Ventas antes de la corrida para ocupar sus localidades habituales; Zabala sobre las puertas de toriles, y Vidal en el tendido bajo del 10. Entremezclados con los aficionados, tomaban notas para redactar unas crónicas que inmediatamente después del festejo se apresuraban a dictar por teléfono. Esta incomodidad física a la que se veían sometidos es un matiz más que hemos tenido en cuenta en la tesis que da lugar a estas líneas.

De hecho, advertimos que la tesis es un estudio de tipo descriptivo, es decir, que aunque ofrece cabida el planteamiento de algunas hipótesis, resulta de mayor relevancia el desarrollo de una investigación fundamentada en la observación, la comparación y la deducción. Sin embargo, la tesis sí que cuenta con una hipótesis principal: demostrar que el ethos funciona como elemento retórico esencial que configura las distintas partes de la crónica taurina.

\section{Un análisis múltiple del ethos retórico}

En este contexto que trazamos para emprender la tesis, nos planteamos una variante más que por obvia no deja de ser relevante. Es imposible escribir sobre una corrida de toros sin considerar que esa obra artística caduca y es fugaz. Además, el público que la observa siente tocado su lado más sensible ante esa expresión estética que influye en sus pasiones. Esto también puede aplicarse, evidentemente, a la persona 
que escribe sobre toros, pues está presenciando como un hombre, un torero, arriesga su vida para llevar a cabo esa creación artística tan efímera como irrepetible. Por ello, buscar el ethos en las crónicas de Vicente Zabala y J oaquín Vidal sobre las actuaciones de Joselito como matador de toros en Madrid ${ }^{1}$ recordamos el concepto aristotélico clásico de ethos, concepto al que después añadimos la definición que hizo Heinrich Lausberg:

"Los afectos suaves tendentes a la captación de la simpatía y del delectare y apropiados para ganarse la afición del público de manera duradera, afectos que también aparecen como disposición permanente del alma" (Lausberg, 1990, p. 257).

Pero también quisimos ampliar esa definición con otras cuestiones como el valor ético-moral del cronista y su universo estilístico a través de un método de análisis, como decimos, múltiple:

1. Como arranque del trabajo, analizamos las crónicas para obtener una primera toma de contacto, a modo de descubrimiento. Para ello, aplicamos la citada definición de crónica taurina que hizo la profesora María Celia Forneas en su obra "Un texto informativo, literario y de opinión". Y observamos que las crónicas estudiadas ofrecen datos, obligan al ejercicio de unas habilidades literarias y reflejan una subjetividad. Tanto es así que da la impresión de que los dos periodistas parecen haber presenciado festejos distintos.

2. Después emprendimos un segundo análisis siguiendo los pasos marcados en la Retórica aristotélica. Es decir, tratamos de distinguir las fases del discurso clásico que se pueden plantear en la crónica taurina: la inventio, o elección del tema sobre el que hablar; la dispositio, o estructura con la que se

\footnotetext{
${ }^{1}$ Desde 1986, año en que Joselito tomó la alternativa, hasta 1995. En diciembre de este año falleció Vicente Zabala y no pudo presenciar los triunfos del madrileño en Las Ventas en 2006.
} 


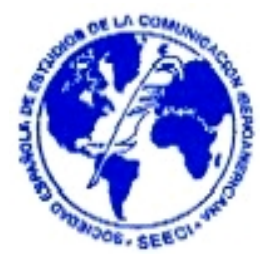

articula el discurso; y la elocutio, o el aderezo retórico con el que se da forma al mensaje.

3. En ese punto, creímos conveniente desarrollar un análisis comparativo entre ambos cronistas. $Y$ en él comprobamos que en las crónicas no sólo se detectan los estilos, el ethos y los valores taurinos de los periodistas, sino también se pueden obtener trazos de la tauromaquia y personalidad del objeto al que se refieren, el toreo de Joselito. Por eso quisimos acotar el ámbito de estudio a las crónicas que tenían en común que hablaban sobre la misma corrida de toros, el mismo torero y la misma plaza.

4. El cuarto, y último, análisis se adentró de nuevo en el ethos de sus autores a través de lo que avanzó Aristóteles en su Retórica, es decir: buscamos las máximas, las referencias a tres grandes protagonistas del espectáculo taurino como son los toros, los toreros - en particular al matador Joselito- y el público, las filias y fobias taurinas 0 no taurinas de los autores, el uso de autorreferencias (personales o profesionales), sus reacciones ante los grandes acontecimientos como son los triunfos y las cogidas, y, también, los valores y el léxico taurinos utilizados. Indudablemente todas estas y otras muchas variables influyen en el modo de contar la corrida.

Dijo el maestro del periodismo taurino Gregorio Corrochano: "En Tauromaquia nunca se sabe si lo que se dice es verdadero, aunque todos creen conocer la verdad" (Corrochano, 1999, p. 24)2. Es decir, que la crónica taurina es, sin lugar a dudas, una narración subjetiva y libre. Por lo tanto, está entre la realidad y la fabulación.

\footnotetext{
${ }^{2}$ Para entender mejor esta afirmación, reproducimos el fragmento completo que la contextualiza:
}

"La mayor dificultad de la crítica taurina está en que falta el objeto de referencia. Todo ha pasado. No queda rastro de la corrida. Alguna fotografía aislada, como documento de autenticidad refleja, si acaso, un momento, un detalle, ni siquiera una suerte completa. Apoyamos la razón en lo que vimos y ya no vemos. Lo que se ve varía con el punto de vista, con la mirada y con lo que hay detrás de la mirada. La buena o mala disposición del que mira, la intención, que es lo que hay detrás de la mirada, es donde se sitúa el mal de ojo. No podemos desconocer que el mal de ojo existe en las plazas de toros. La crítica, aunque sea sincera, serena, juiciosa y docta, como tiene su origen en la mirada, no tiene fundamento estable. En tauromaquia nunca se sabe si lo que se dice es verdadero, aunque todos creen conocer la verdad. ¿Es que estoy yo seguro de lo que digo? Si no lo estoy, ¿por qué me atrevo a definir? No me atrevo. Voy 
Hernández Pérez, Ma Almudena (2010): La crónica taurina: El Ethos retórico de Vicente Zabala y Joaquín Vidal. No 21. Marzo. Año XIV. Páginas: 71-93

ISSN: 1576-3420 DOI: http://dx.doi.org/10.15198/seeci.2010.21.71-93

También debemos recordar que la crónica está realizada por aficionados. Y, si como dijo J uan Belmonte "se torea como se es", podríamos añadir que además "se escribe como se es".

\subsection{La búsqueda del ethos en las crónicas de Vicente Zabala}

\subsubsection{Breve repaso biográfico a Vicente Zabala}

Para buscar el "alma retórica" de las crónicas de Vicente Zabala Portolés, primero trazamos un breve perfil biográfico. Para continuar con este resumen, recordaremos algunos de los detalles más característicos. Zabala dirigió la sección taurina del diario $A B C$ durante más de dos décadas. Falleció en un accidente aéreo en diciembre de 1995, en plena campaña taurina americana. Durante su trayectoria contó con el respeto de los profesionales taurinos, aunque siempre dijo que no quería intimar con toreros, ganaderos, empresarios y apoderados, lo que se conoce en el ámbito de la fiesta brava como "taurinear".

Zabala Portolés nació en Madrid el 27 de enero de 1937. En el momento del siniestro aéreo tenía 58 años. Su infancia la vivió en Sevilla, ciudad donde aprendió a leer y realizó sus estudios primarios. Los secundarios los cursó en Madrid, donde emprendió la carrera de Periodismo en la Escuela de la Iglesia y también en la Oficial. En las cubiertas de su obra "La entraña del toreo" descubrimos que para obtener esa doble graduación había presentado una tesis académica de fin de carrera sobre la historia de la crítica taurina (Zabala, 1968).

Debutó como informador taurino en la Agencia Logos, de la Editorial Católica, en 1960. Dos años después, fue nombrado redactor jefe del semanario taurino Fiesta Española y, en 1964, empezó a colaborar en la revista de toros El Ruedo. Cuando 
murió, en diciembre de 1995, hacía 23 años que había accedido a la jefatura de la sección taurina de $A B C$, donde en 1972 sucedió al famoso crítico taurino Antonio Díaz Cañabate.

A su biografía profesional se pueden añadir otros datos, como que sobre el año 1965 se había hecho cargo de la crítica taurina del diario vespertino El Alcázar, editado por Pesa. De ahí, Zabala pasó a ocupar la tribuna taurina del Nuevo Diario, de la misma empresa. En estos últimos años sesenta creó el programa Revista de Toros, de Televisión Española, en el que se mantuvo hasta 1973.

También, en los últimos años de la década anterior, es nombrado cronista taurino de Blanco y Negro, sustituyendo en el puesto al académico e historiador José María de Cossío. No era la primera participación de Vicente Zabala en Prensa Española, pues había colaborado en la sección cultural del periódico. También colaboró en la Agencia Efe (1977-1985), en Antena 3 Radio y Antena 3 Televisión, además de Balcón Taurino - que dirigió- y la revista taurina Aplausos.

Para entender su trayectoria profesional como periodista debería considerarse también su afición a los toros. Vicente Zabala se había iniciado en el espectáculo taurino desde niño y en la adolescencia se acercó a la familia Bienvenida, con cuyos miembros forjó una fuerte amistad. Además, se casó con Peñuca de la Serna y Ernst, hija del torero Victoriano de la Serna.

Esa afición queda reflejada por su propia pluma. En 1987, según puede leerse en otro de sus libros, "Tiempo de esperanza", Vicente Zabala afirmaba que acababa de cumplir "sus bodas de plata profesionales", con "más de 3.500 corridas presenciadas" durante 25 temporadas. Confesaba que había estudiado Periodismo para expresar con su pluma lo que veía en el ruedo y sobre lo que debatía en la peña taurina "Los de Hoy" que fundó. Leemos que había observado que "muchas veces lo 
que veía en la plaza no lo leía al día siguiente en los periódicos, ni tampoco en los semanarios sobre la Fiesta de Toros"( $A B C, 22$ de diciembre de 1995).

En el libro titulado La entraña del toreo, Zabala reflejó lo que supone hacer crítica taurina:

"El género periodístico de la crítica taurina, con propia personalidad y no poca calidad literaria en todos o casi todos los críticos citados [se refiere a Giraldillo, García Rojo, Antonio Bellón, Alardi, Capdevila, Federico Alcázar, Clarito, K-Hito...] no me acaba de satisfacer plenamente. El aspecto informativo, al contrastarlo con lo acontecido en el redondel, me sumía en un auténtico mar de confusiones. Junto a la crítica veraz no faltaban otras con cierto tufillo de mediatización - 'publicidad' lo llaman ahora-, que me hizo buscar por otros cauces la forma de conocer a fondo los problemas de la Fiesta, el por qué de cuanto se realizaba en el albero, las reacciones de los toros, la ciencia del arte del toreo. Quería - necesitaba - pulsar dónde terminaba la verdad y dónde comenzaba el fraude" (Zabala, 1968, p. 16).

Zabala publicó varios libros (La entraña del toreo, La ley de la Fiesta, Hablan los viejos colosos del toreo, Restauremos nuestra Fiesta Nacional, Tiempo de esperanza, entre otros) y recibió diversos premios. Sus conocidos dicen que se sabía "de pe a pa la historia del toreo" y que en sus crónicas se refería "a los recuerdos juveniles de los toreros de su niñez y de todos aquellos que habían contribuido a hacer grande la tradición de la Fiesta Nacional", según aquel despliegue de $A B C$. El citado Javier Villán, escribe así sobre Vicente Zabala Portolés:

"Cuando Vicente Zabala murió en 1995 [...] los buenos aficionados a los toros exhumaron de sus recuerdos lo que más carácter dio a su 
Hernández Pérez, Ma Almudena (2010): La crónica taurina: El Ethos retórico de Vicente Zabala y Joaquín Vidal. No 21. Marzo. Año XIV. Páginas: 71-93

dilatada carrera de crítico taurino: la cruzada de sus primeros tiempos contra la corrupción y el 'sobre' y su gallardía frente a la impostura de "El Cordobés". [...] La autoridad que alcanzó Zabala está ligada a esa actitud insumisa de los años sesenta y primeros setenta y, posteriormente, a la solera histórica de las páginas taurinas de $A B C$. En un ambiente viciado de la crítica taurina, en una alarmante depresión de sus supuestos éticos y orientadores, Vicente Zabala alzó una voz que, entonces, muchos consideraron excesiva y que fue parte importante de un movimiento liberador. El mérito de Zabala fue elegir la oportunidad y el tono; aprovechó la necesidad histórica y fue un revulsivo contra el conformismo. [...] Estos fueron los primeros tiempos de Zabala y eso no tiene vuelta de hoja, aunque más tarde atemperara su fuego libertador. Zabala puso el foco en los vicios de la Fiesta $y$, de resultas, los focos se centraron de nuevo en la importancia de la crítica taurina como contrapoder. Aunque más tarde rebajara su tono, [....] y fueran, Navalón primero y Vidal después, los más justicieros" (Villán, 2006, p. 361).

\subsubsection{Manifestaciones del ethos de las crónicas de Zabala}

En las crónicas estudiadas fuimos trazando el ethos de Zabala según ese múltiple análisis que hicimos. Para empezar, se ve que el autor usa la primera persona y ofrece consejos a los toreros y a los demás protagonistas del orbe taurino. Sus crónicas tienen un tono sobrio, nostálgico, muestran sus inclinaciones políticas, su apoyo a la Corona -algo a lo que también acostumbra el $A B C$ - y dan pistas sobre su círculo de amistades. Se puede decir además que Vicente Zabala era un "castizo" de Sevilla, pues parece que su corazón estaba dividido, entre Madrid y Sevilla, taurinamente hablando. 


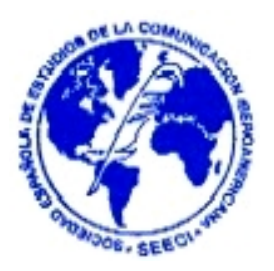

En esa nostalgia que impregna sus crónicas destaca especialmente el nombre de una estirpe torera, la de los Bienvenida, con cuyos miembros le unía una gran amistad y admiración. Sin embargo, Vicente Zabala no se obceca en su reconocido bienvenidismo cuando tiene que destacar los méritos de otros toreros, algo que también hizo reconociendo, cuando la ocasión lo merecía, con Joselito. No obstante, se detecta el matiz de que Zabala no le perdonó al espada madrileño que se apodase como el matador sevillano J osé Gómez Ortega, Gallito, conocido como Joselito 3.

Otra de las observaciones que podemos hacer tras el análisis de las crónicas de Vicente Zabala es que deja a los toros en un segundo plano, pues parece que prefiere ocuparse de hablar de los toreros, las negociaciones de los apoderados con las empresas de las plazas, el público y la política. Sin embargo, cuando alude al ganado, denuncia la falta de fuerza, mansedumbre y presentación de los toros. De hecho, Zabala reclama calidad en el toro y que se recobre la casta y la variedad ganadera.

Finalmente, cuando el periodista presta atención al público suele ser para hablar del famoso tendido 7 de la plaza de Las Ventas, y compara a los espectadores de este coso con otras aficiones, como la de Sevilla y Pamplona. También alude al señoriteo y a sus amistades. En ocasiones va más allá, y se convierte en protagonista y, a través de autorreferencias, forma parte del público del que habla en sus crónicas.

\footnotetext{
${ }^{3}$ Algunas de estas cuestiones se aprecian en la crónica "¡Y no estaban las figuras..!" ( $A B C, 31$ de mayo de 1986): "El público enfilaba hoy la calle de Alcalá arriba en ese lento y delicioso, esperanzador e ilusionado, caminar hacia las Ventas diciendo que iban a ver a Joselito. Ni más ni menos. Un poco fuerte suena eso ¿Verdad usted? El chaval madrileño ha elegido un apodo que cuando se fija uno en los carteles entra un no se qué por el cuerpo... Hace muchísimos años me decía don Manuel Bienvenida, en la terraza de la torera casa de General Mola mientras contemplaba a sus hijos en el ajetreo del toreo de salón en el jardín, que cuando murió Joselito decía la gente que se habían extinguido para siempre las escuelas taurinas. No iba el Papa Negro por las escuelas propiamente dichas, tal y como las entendemos hoy a través de esas escuelas patrocinadas por Ayuntamientos y Comunidades Autónomas de las que procede este Joselito de hoy, precoz y despabilado, sino a lo que se entendía como torero de escuela".
} 


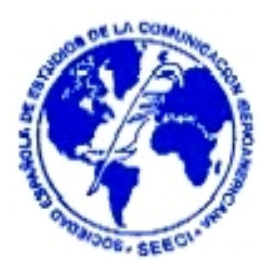

En el análisis de las crónicas según las fases de elaboración del discurso que marcaba Aristóteles, hemos visto que en la inventio Zabala utiliza la línea psicológica, por ejemplo, para apelar al público, a los toreros o al lector para justificar sus planteamientos.

En la segunda fase, la de la dispositio, observamos que los titulares suelen ser nominales y largos, y que los textos guardan un esquema básico. Primero utiliza una larga digresión, fruto quizás del gran espacio con el que trabaja (casi una doble página para la crónica del día), en la que se ofrecen algunas hipótesis. Esa digresión suele comenzar en la entradilla, que no responde a la técnica informativa de responder a las cinco preguntas (qué, quién, cuándo, dónde y por qué), lo que retrasa la crónica en sí, ofreciendo primero un relato más social y costumbrista. En segundo lugar se ocupa de la labor de los toreros, normalmente por orden de actuación de éstos y a veces de antigüedad. Y en tercer y último lugar remata sus crónicas con un breve párrafo a modo de conclusión y resumen.

Durante los análisis efectuados para aproximarnos al máximo al ethos retórico de Zabala, también apreciamos la forma en que el autor reaccionaba ante los acontecimientos. Por ejemplo, cuando la crónica versa sobre una cogida o un gran triunfo, el periodista vuelca en su texto un tono dramático o jubiloso, llegando incluso a reconocer que está improvisando ${ }^{4}$.

Pero no sólo hemos pretendido acercarnos al alma retórica del autor a través de los contenidos de las crónicas. También hemos prestado cierta consideración al modo de presentarlos, a la forma que adquieren los textos en las páginas de $A B C$. Por ejemplo, respecto al uso de elementos gráficos, hemos observado que parece que Zabala utiliza los ladillos como una herramienta que tiene un papel más narrativo que

\footnotetext{
${ }^{4}$ Un ejemplo de esto que decimos lo encontramos en la crónica "Gravísima cogida del peón Antonio González" ( $A B C, 23$ de mayo de 1988): "La cosa no estaba para bromas ni nosotros tenemos, en el momento de transmitir urgentemente desde un teléfono de la plaza esta crónica absolutamente improvisada, el ánimo para hablar de pases naturales y derechazos".
} 
Hernández Pérez, Ma Almudena (2010): La crónica taurina: El Ethos retórico de Vicente Zabala y Joaquín Vidal. No 21. Marzo. Año XIV. Páginas: 71-93

ISSN: 1576-3420 DOI: http://dx.doi.org/10.15198/seeci.2010.21.71-93

estético, y que al igual que los pies de foto, sumarios e ilustraciones, le permiten mostrar sus opiniones sobre la corrida o sobre otras cuestiones del planeta taurino.

En la fase de la elocutio o del aderezo retórico del discurso es cuando aparece el concepto de Tauromaquia que tenía Zabala Portolés. Y lo vemos a través de las citas, ejemplos, recuerdos, anécdotas y vivencias de las que se vale; de la inclusión del periodismo dentro del periodismo con autorreferencias (normalmente para defender su imparcialidad y método de hacer las crónicas); y de la utilización de los estilos movere, delectare y docere.

\subsection{La búsqueda del ethos en las crónicas de Joaquín Vidal}

\subsubsection{Breve repaso biográfico a Joaquín Vidal}

Joaquín Vidal Vizcarro, cuyas crónicas analizamos en el diario El País, también estudió en la Escuela Oficial de Periodismo (entre 1960 y 1963). Comenzó a escribir en el diario Hierro y después en Pueblo e Informaciones de Madrid y fue jefe de prensa del Instituto Social de la Marina.

Antes de entrar en El País escribía de toros una columna satírica en el semanario humorístico La Codorniz, bajo el título "Las vacas enviudan a las cinco". Como veremos más adelante, la ironía que practicó en estas colaboraciones le acompañó siempre, incluso en las crónicas taurinas que estudiamos en la tesis que comentamos. También fue autor de temas extrataurinos, practicó el reportaje, la entrevista y la columna, colaboró en la Cadena SER y escribió crónicas en la Gaceta Ilustrada, La Actualidad Española y Nuevo Diario. Publicó asimismo en Taurología.

En cuanto al modo de escribir, podemos decir que este periodista "es otro gran defensor del toreo en su plenitud y belleza. Su estilo es certero, con un punzante sentido del humor, con una dialéctica prácticamente invulnerable, convincente, de 
una valerosa objetividad. Su crítica se ha revelado, en su coherencia y orden, como un testimonio imprescindible del toreo de nuestros días" (AA.VV., 2007, tomo 8, p. 645). Como observamos con Vicente Zabala, también J oaquín Vidal volcaba en sus crónicas sus propias teorías sobre la Tauromaquia, según comenta El Cossío:

"Periodista de grandes recursos literarios, ha sido un defensor de la pureza de la Fiesta y ha influido notablemente en la afición madrileña con su defensa de la ganadería brava y de su propia concepción de la Tauromaquia. Muchos consideran que esta defensa solo ha dado lugar a un culto equivocado del toro de gran peso y genio en detrimento de su bravura y movilidad. Poco transigente con figuras del toreo y los ganaderos, Vidal era excesivamente crítico al juzgar el espectáculo. Beligerante y reivindicativo, se granjeó antipatías en todo el mundo profesional taurino, pero sus crónicas de El País durante más de un cuarto de siglo fueron y son un punto de referencia en la historia de la tauromaquia" (Pizarroso, 2007, tomo 30, p. 278).

Este perfil lo amplía el crítico J avier Villán, que compartió con él tardes de toros, con el siguiente retrato:

"Ironía, humor a veces sarcástico $y$, casi siempre, un fondo de melancolía sobredorada por un excelente lenguaje. A todas las figuras señeras de la crónica taurina se les ha acusado siempre de lo mismo: antitaurinos; y pésimos aficionados, aunque buenos escritores. Es la venganza del sistema, de los intereses perversos que, con las lógicas excepciones, en vez de servir a la Fiesta, se aprovechan de ella. Joaquín Vidal era un excelente escritor $y$, por descontado, amaba la Fiesta. Es imposible no amarla y, sin más premio, viático o bicoca que el sueldo de un periódico, escribir al año 
centenar y medio de crónicas. Y hacerlo con la excepcional prosa de Joaquín" (Villán, 2006, p. 377).

Joaquín Vidal marcó la filosofía de la información taurina del diario El País, de cuya redacción fue miembro fundacional. María Cruz Seoane y Susana Sueiro, en Una historia de El País y del grupo Prisa, confirman que en la sección "La Lidia" de El País sólo hay un nombre, el de Joaquín Vidal:

"En cuanto a los toros, según Joaquín Vidal, que se ocupó de la sección "La Lidia" (tras un brevísimo paso por ella de Alfredo Corrochano), encuadrada al principio en Deportes, había mucha curiosidad entre taurinos, intelectuales y periodistas antes de la salida del periódico: daban por seguro que no se ocuparía de ellos por tratarse de un periódico con vocación europea: 'Estamos en España -le dijo Cebrián- donde la Fiesta constituye una realidad social y compartimos la idea orteguiana de que forma parte de nuestra cultura'. Sin embargo, son muchos los aficionados que estiman que el periódico se ocupa muy poco de la Fiesta [...]. Claro que a otros lectores, ferozmente antitaurinos, les gustaría que El País hubiera imitado en esto a El Sol. Es la vieja polémica, que se remonta al siglo XVIII, entre defensores y detractores del antiguo espectáculo" (Seoane \& Sueiro, 2004, p.68)

Como leemos en El País a la muerte de su cronista taurino, Vidal había escrito en este periódico más de 5.000 artículos. Su compañero de redacción Miguel Mora cita el último, del 19 de marzo, "Temporada". Decía el periodista taurino:

"Sabe un servidor que le llamarán derrotista y enemigo de la Fiesta. En esta cuestión (y en otras, no se crea) tiene amplia experiencia. También dirán, por lo mismo, que no sabe escribir de toros. Sin 
embargo, tampoco conviene ser tan radical. Algunas veces sí sabe (más o menos). Dicho sea sin ánimo de ofender y mejorando lo presente" (El País, 11 de abril de 2002).

Mora continúa refiriéndose al "radicalmente negativo" diagnóstico del estado de la Fiesta de Vidal. Añade que era, "no por nostalgia, sino por una defensa feroz de la integridad del espectáculo", de ahí que el crítico diese "leña" en sus crónicas "a los isidros, los figurones que torean con el pico de la muleta y a base de derechazos, los subalternos que dan consignas absurdas desde el burladero ('toca, toca'), los empresarios golfos, los picadores que tapan la salida y hacen la carioca, los ganaderos que crían toritos que se caían yertos en el ruedo".

El estilo del crítico taurino de El País, como cuenta Mora, tendría seguramente una influencia de las condiciones en que escribía Vidal, "metido en el chiscón de un garaje cercano, con poca luz y menos tiempo, entre coches y humos", desde donde "mandaba la ficha y luego un texto impecable y un pie de foto editorializante".

Con la afición heredada de su padre, llegó desde el norte a Madrid con apenas cuatro años. Luego esa afición fue aumentando hasta el punto de que prefería leer E/ Cossío a irse al madrileño parque del Retiro como hacían los jóvenes de su edad. Entre sus toreros favoritos figuraba un carte/ compuesto por Antonio Bienvenida, Curro Romero y Rafael de Paula. Con los años, también se inclinó por los "modestos" como José Pedro Prados El Fundi, Víctor Puerto o Domingo Valderrama, y por las dotes lidiadoras de Luis Francisco Esplá.

El propio Esplá hablaba en exclusiva para la tesis que comentamos sobre Joaquín Vidal: "Era un tío muy divertido. Manejaba un humor muy tipo Gómez de la Serna, ese humor castizo y muy fino, sutil, tan bien desglosado, como habrá visto usted en sus crónicas". A lo que añadía: "Era entrañable. [...] Todo lo que en las crónicas puede traslucir severidad, rigor, dureza, porque son así muchas de ellas, en persona 
Hernández Pérez, Ma Almudena (2010): La crónica taurina: El Ethos retórico de Vicente Zabala y Joaquín Vidal. No 21. Marzo. Año XIV. Páginas: 71-93

no tenía nada que ver" (Hernández, 2009, p. 504). En resumen, según el torero levantino, "era buen aficionado". "Lo que pasa es que yo creo que en ese aspecto era demasiado riguroso. El espectro de los toreros y el espectro del toro que él tenía era muy ceñido, estaba muy circunscrito a una fórmula. En ese aspecto sí que reconozco que no tenía ese espectro amplio de otros críticos", concluye el torero.

Pero en las líneas siguientes entenderemos un poco mejor el ethos de Joaquín Vidal. En 40 años después. Temporada taurina 1987, libro publicado al cumplirse cuatro décadas de la muerte del torero Manuel Rodríguez "Manolete", se recoge una particular crónica escrita por el periodista de El País. En ella indica que "la vida de un crítico taurino deslumbra a tres, y los tres están mal deslumbrados". A continuación se plantea la tesitura de un crítico que tuviera que escribir una crónica contando su vida, "siempre obligado por las circunstancias, naturalmente; por ejemplo, en casos de amenaza de cese fulminante", una realidad que tendría que contar "desde la veracidad más estricta" (Vidal, 1988, p. 50). Luego, sobre el papel del crítico taurino, teoriza:

"La función del crítico taurino, entiendo, debe ser principalmente periodística. La crítica taurina es una modalidad, entre muchas, del periodismo, y su visión primera ha de ser informar. Tiene también otras, naturalmente, pues tratándose de crítica, es preciso que dé su opinión y ésa ha de ser rigurosamente honesta, en todas sus vertientes: de lo visto, la verdad; de su exposición, la sinceridad; de su análisis, la preparación de base precisa, que ha de aplicar al estudio responsable de lo acontecido. En la crónica no es forzoso - ni siquiera conveniente- que tengan un lugar uniforme y cronológico todos los elementos de la corrida vista. La omisión consciente y responsable, la alteración del orden de lo sucedido en función de su importancia, también son formas de crítica, y ahí han de entrar, por fuerza, las 
normas del periodismo, y a su vez, el estilo de cada cual; siempre éste subordinado a aquéllos" (I bid. P. 52).

En sus crónicas el periodista no sólo habla de los toros y de los toreros, también da protagonismo especial a los públicos, y dentro de éstos, incluye a ciertos sectores de la plaza de toros de Madrid, con los que Vidal muestra su afinidad, como la andanada del 8 de Las Ventas, donde "se concentran los mejores aficionados", y "en el tendido bajo del 7", escribió en El toreo es grandeza (I bid. P. 62).

\subsubsection{Manifestaciones del ethos de las crónicas de Vidal}

Basándonos en el análisis de las crónicas, según las conclusiones de la tesis "J. M. Arroyo Joselito, análisis de sus actuaciones en la plaza de Las Ventas: las crónicas de ABC $y$ El País", se observa que Vidal ejerce un periodismo taurino de denuncia de las irregularidades de la Fiesta (denuncia a la que contribuyen también las fotos elegidas) que refleja ese tono más negativo del espectáculo. Esta característica, quizás, permite ampliar las fronteras de su público, pues Joaquín Vidal era leído también por muchos no aficionados, que acudían a sus crónicas por cultura y deleite literario.

Sin embargo, en la citada tesis se corrobora que Vidal fue buen aficionado y que, como tal, supo descubrir posibilidades en muchos toreros como fue el caso de Joselito. Cuando Vidal se enfrentaba a triunfos, según se ve en sus crónicas, se dejaba llevar por el sentimiento y la literatura; mientras que si la lidia era desafortunada o no acertada, utilizaba la ironía y el humor más ácidos, dos recursos también necesarios.

La citada tesis refleja que las crónicas de Vidal son una suma de poesía, humor, buena pluma, léxico taurino, lenguaje culto y lenguaje popular. Vemos algunas de estas cuestiones en la crónica del 28 de mayo de 1988, titulada "Torear es asf": 
"Estábamos en qué es torear, a estas alturas aún, medio siglo después de que Belmonte dijera cómo. Estábamos en qué torear es, según algunos, dar pases sueltos con su aderezo de agitación y pico; según otros, Don Tancredo con un trapo, cuando subió ayer Joselito al encerado y explicó que es así, el toro traído hacia el terreno del torero, el torero ganándole terreno al toro: encuentro, armonía, dominio. Hubo un grito en el tendido: 'AAntoñete, aprende de tu nieto!' Qué va a aprender Antoñete, si es el Catón. Pero alguna verdad subyacía en aquella frase hiriente: Joselito sí es nieto de Antoñete, nieto ideológico, aprendiz de sus enseñanzas, admirador de su honesta ejecutoria, imitador de su hombría torera" (El País, 28 de mayo de 1988).

En cuanto a las fases de elaboración del discurso, en la tesis se descubre que en la inventio Vidal muestra al menos dos Joselitos, el de los inicios, en los años 80 , un torero prometedor; y el de sus últimos años de actividad, en el que se muestra a un torero que ya no sorprende tanto. Pero hay algo que destaca sobremanera en sus crónicas, la defensa del "toro-toro". Y esa defensa la hace a través de referencias al público (en especial al tendido 7), y criticando a colectivos cuya imagen de toro ideal quizás no coincide con la del periodista, como son los "taurinos" (esos profesionales y personajes que merodean en el planeta de los toros), y lo que el propio Vidal citó como el joselitismo, el numeroso grupo de seguidores de Joselito.

Leemos en la crónica titulada "Una oreja porque si":

"A la pareja que tenía atrás ayer le sorprendió enormemente el paseillo. Preguntaba ella: ¿Por qué se van hacia la derecha si están las capas a la izquierda?' Respondía él: 'No les han debido avisar y van al buen tun tun'. Poco después, al ver cómo los toreros llegaban 
a la barrera y se deshacían en reverencias, la chica averiguó el motivo: 'AAh, claro! No me había dado cuenta. Es que está ahí arriba la madre del Rey y la cumplimentan'. Tarde adelante la pareja hizo uso de sus derechos democráticos, pidió la oreja para Joselito y les colmó de felicidad que sus deseos fueran satisfechos" (El País, 16 de mayo de 1997).

En la dispositio, las crónicas analizadas de Joaquín Vidal suelen responder a una estructura estable, de tres partes, aunque siguiendo un esquema narrativo circular marcado por un hilo conductor o tema. Sus titulares son breves, a veces de una sola palabra, lo que obliga a leer el texto para entender completamente su significado. Dado el diseño de El País, las crónicas son más breves y más ágiles, característica provocada por la buena pluma del autor. Todo ello contribuye, sin duda, a que sean crónicas accesibles al lector no iniciado. Respecto a cómo afronta los acontecimientos, Joaquín Vidal se muestra afectado ante los percances que suceden en el ruedo y de los que es testigo, para los que suele buscar razones y explicar los motivos por los que se produjeron.

Por último, en la tercera fase de elaboración del discurso, la elocutio, hemos descubierto a un Joaquín Vidal que usa preguntas retóricas, hipérboles, metáforas, citas y adjetivos, y que estos suelen ser numerosos, variados y sonoros especialmente cuando forman parte de descripciones de toros, pues este autor siempre mira al toro para juzgar al torero.

\section{A modo de conclusión}

Como hemos visto en Vicente Zabala y Joaquín Vidal, a través de las crónicas que escribieron refiriéndose a las actuaciones de José Miguel Arroyo en Las Ventas, se demuestra la hipótesis que nos planteábamos en la tesis: que el ethos retórico es un 
elemento configurador de las crónicas taurinas. Pero, podemos apuntar algo que va más allá.

En la tesis también se alcanzaron algunas conclusiones sobre José Miguel Arroyo Joselito. Como ocurre con cualquier torero, el hecho de vestir el traje de luces le convierte a Joselito en héroe y víctima. Una dualidad que, por lo visto en las crónicas, percibe el público y la prensa.

Además, también se puede decir que si el ethos que analizábamos en la tesis, implica plasmar el talante y el carácter del autor en la retórica de sus crónicas, también vemos que Joselito lo plasma en su creación, que no es otra que la lidia de un toro. Un carácter que, como persona, puede estar influenciado por múltiples circunstancias.

\section{Bibliografía y Hemerotecografía}

AA.VV. (1995): $A B C 22$ de diciembre.

AA.VV. (2007): El Cossío. Los Toros, Espasa Calpe, Madrid.

ARISTÓTELES (1990): Retórica, Editorial Gredos, Madrid. (Quintín Racionero, traductor introducción y notas).

CHAVES NOGALES, Manuel (2009): Juan Belmonte. Matador de toros. Libros del Asteroide, Barcelona.

CORROCHANO, Gregorio (1999): Tauromaquia (Volumen que incluye ¿Qué es torear?, Teoría de las corridas de toros y Cuando suena el clarín), Espasa Calpe, Madrid.

FORNEAS, María Celia (1998): La crónica taurina actual. Un texto informativo, literario y de opinión, Biblioteca Nueva, Madrid. 
HERNÁNDEZ, Mạ A. (2009): J. M. Arroyo Joselito. Análisis de sus actuaciones en la plaza de Las Ventas: las crónicas de $A B C$ y El País (tesis doctoral). Consulta en la Biblioteca de la Facultad de Ciencias de la Información de la Universidad Complutense de Madrid, Madrid.

LAUSBERG, Heinrich (1990): Manual de Retórica Literaria. Fundamentos de una Ciencia de la Literatura, Gredos, Madrid.

SEOANE M. C., SUEIRO S. (2004): Una Historia de El País y del Grupo Prisa. De una aventura industria a una gran industria cultural, Plaza y Janés, Barcelona.

VIDAL, J oaquín (1988): 40 años después. Temporada taurina de 1987, Espasa Calpe, Madrid.

VIDAL, J oaquín (1988): "Torear es así", El País, 28 de mayo.

VIDAL, Joaquín (1997): “Una oreja porque sí”, El País, 16 de mayo.

VILLÁN, Javier (2006): La crítica taurina. Antología, Marenostrum, Madrid.

VILLÁN J. (2007): "Regeneracionismo y calidad literaria", en - AA.VV.: El Cossío. Los Toros, Espasa Calpe, Madrid. Tomo 30.

ZABALA, Vicente (1968): La entraña del toreo, Prensa Española, Madrid.

ZABALA, Vicente (1986): "¡Y no estaban las figuras..!", $A B C, 31$ de mayo.

ZABALA, Vicente (1987): Tiempo de esperanza. Ante la temporada taurina de 1987, Espasa Calpe, Madrid.

ZABALA, Vicente (1986): "¡Y no estaban las figuras..!", $A B C, 31$ de mayo.

ZABALA, Vicente (1988): “Gravísima cogida del peón Antonio González", $A B C, 23$ de mayo. 